\title{
Teams Games Tournament (TGT) sebagai strategi mengaktifkan kelas dengan mahasiswa yang mengalami hambatan komunikasi
}

\author{
Rafika Rahmawati \\ Fakultas Ilmu Pendidikan. Jl Colombo Nomor 1, Karangmalang, Yogyakarta, 55281, Indonesia \\ * Corresponding Author. E-mail: rafika@uny.ac.id,
}

\begin{abstract}
Abstrak: Peran aktif setiap mahasiswa di dalam kelas saat pembelajaran sangat mendukung keberhasilan proses belajar yang menyenangkan. Setiap elemen memiliki dukungan terhadap berhasilnya pembelajaran. Mahasiswa dengan hambatan komunikasi memiliki masalah terhadap peran aktif-nya didalam pembelajaran. Ada beberapa karakteristik yang dimiliki mahasiswa hambatan komunikasi yang menyebabkan mereka tidak percaya diri dan tertutup serta cenderung tidak berbaur dengan teman sekelas. Melalui teams games tournament kelas diaktifkan dengan membagi mereka kedalam kelompok kecil, dimana setiap kelompok melakukan presentasi dengan mengambil tema "kebutuhan komunikasi setiap anak hambatan majemuk". Setiap kelompok wajib melakukan presentasi dan setiap kelompok yang lain wajib menyampaikan pertanyaan kepada kelompok yang sedang presentasi. Setiap kelompok dan anggota kelas memiliki kesempatan yang sama termasuk mahasiswa dengan hambatan komunikasi. Peraturan yang diterapkan tersebut membuat mahasiswa dengan hambatan komunikasi juga mendapatkan kewajiban untuk melontarkan pertanyaan dan menjawab pertanyaan dari teman yang lain. Peraturan yang diterapkan dalam TGT tersebut mampu membuat mahasiswa hambatan komunikasi tersebut berperan aktif di dalam kelas.
\end{abstract}

Kata kunci: Pembelajaran Aktif, Hambatan Komunikasi, Teams Games Tournament (TGT)

\section{Teams Games Tournament (TGT) as learning strategy to built active class for student with communication barrier}

\begin{abstract}
The active role of each student in the classroom during learning supports the success of a fun learning process. Each element has support for the success of learning. Students with communication barriers have problems with their active role in learning. There are some characteristics that students have communication barriers that cause them not to be confident and closed and tend not to mingle with classmates. Through the team games tournament class is activated by dividing them into small groups, where each group makes a presentation by taking the theme "communication needs of each child multiple obstacles". Each group must make a presentation and each other group must submit questions to the group that is presenting. Each group and class members have the same opportunity including students with communication barriers. The regulations that are applied make students with communication barriers also get the obligation to ask questions and answer questions from other friends. The regulations applied in the TGT are able to make students the communication barriers to play an active role in the classroom.
\end{abstract}

Keywords: Active Learning, Communication Barriers, Teams Games Tournament (TGT)

\section{PENDAHULUAN}

Komunikasi merupakan suatu hal yang penting dalam melakukan kegiatan interaksi. Hal ini juga disampaikan oleh Dance dan Stappers, 1970 (Liliweri, 1997: 5) memaknai komunikasi ke dalam beberapa makna diantaranya adalah komunikasi sebagai aktifitas dari satu pihak, aktifitas datang dari pihak lain sehingga terjadi pengaruh mempengaruhi, komunikasi menekankan hubungan, komunikasi menekankan Sharing atau kepemilikan, komunikasi sebagai transmisi informasi, komunikasi sebagai penggunaan lambang dan isyarat. Berdasarkan beberapa makna komunikasi maka dapat ditarik inti yaitu komunikasi sebagai proses social, komunikasi sebagai peristiwa, komunikasi sebagai ilmu, komunikasi sebagai kiat atau keterampilan.

Komunikasi merupakan syarat wajib terjadinya sebuah interaksi social. Interaksi social dapat diciptakan dari beberapa pola-pola hubungan, misalnya sebuah kelompok, antara individu satu dengan 


\section{JPK (J urnal Pendidikan Khusus), 14 (2), 2018 - 71}

Rafika Rahmawati

individu yang lain. Keterampilan komunikasi sudah seharusnya dimiliki oleh setiap individu. Hal ini juga berarti anak berkebutuhan khusus juga perlu untuk mendapatkannya. Mahasiswa juga dituntun untuk bisa berkomunikasi dengan baik sesuai dengan situasi dan kondisi dalam berbagai hal.

Peran aktif setiap mahasiswa di dalam kelas saat pembelajaran sangat mendukung keberhasilan proses belajar yang menyenangkan. Setiap elemen memiliki dukungan terhadap berhasilnya pembelajaran. Mahasiswa dengan hambatan komunikasi memiliki masalah terhadap peran aktif-nya didalam pembelajaran. Ada beberapa karakteristik yang dimiliki mahasiswa hambatan komunikasi yang menyebabkan mereka tidak percaya diri dan tertutup serta cenderung tidak berbaur dengan teman sekelas. Melalui teams games tournament kelas diaktifkan dengan membagi mereka kedalam kelompok kecil, dimana setiap kelompok melakukan presentasi dengan mengambil tema "kebutuhan komunikasi setiap anak hambatan majemuk". Setiap kelompok wajib melakukan presentasi dan setiap kelompok yang lain wajib menyampaikan pertanyaan kepada kelompok yang sedang presentasi. Setiap kelompok dan anggota kelas memiliki kesempatan yang sama termasuk mahasiswa dengan hambatan komunikasi. Peraturan yang diterapkan tersebut membuat mahasiswa dengan hambatan komunikasi juga mendapatkan kewajiban untuk melontarkan pertanyaan dan menjawab pertanyaan dari teman yang lain. Peraturan yang diterapkan dalam TGT tersebut mampu membuat mahasiswa hambatan komunikasi tersebut berperan aktif di dalam kelas.

Menurut Annisa Rahmi Yanti Z, dkk, (2014) salah satu model pembelajaran yang mengutamakan dan memfokuskan kerjasama antar siswa melalui diskusi adalah cooperative learning atau pembelajaran kooperatif. Pembelajaran kooperatif merupakan salah satu model pembelajaran yang menekankan kepada cara siswa belajar dan bekerja dalam kelompok-kelompok kecil secara kolaboratif yang anggotannya terdiri dari 2-5 orang dengan struktur kelompok yang bersifat heterogen.

Adapun tujuan dalam pengelompokan siswa ini supaya beberapa siswa yang kurang mampu tidak merasa minder terhadap rekan-rekan mereka. Selain itu, dalam model ini siswa memiliki dua tanggung jawab, yaitu mereka belajar untuk dirinya sendiri dan membantu sesama anggota kelompok untuk belajar. Sehingga, tujuan dalam penelitian ini adalah untuk mengetahui peran aktif mahasiswa yang memiliki hambatan komunikasi. Diharapkan dengan adanya penerapan dalam pembelajaran kooperatif, mahasiswa yang mengalami hambatan komunikasi dapat menjalin kerjasama dan saling membantu untuk mempelajari suatu materi pelajaran dan tugas-tugas yang diberikan oleh dosen dengan baik.

5 unsur pembelajaran kooperatif yang ditetapkan agar mencapai hasil pembelajaran yang maksimal antara lain 1) saling ketergantungan positif : hubungan yang saling membutuhkan antara siswa satu dengan siswa lainnya untuk menciptakan kelompok kerja yang efektif. 2) tanggung jawab perseorangan : Model pembelajaran ini membuat persiapan dan menyusun tugas sedemikian rupa, sehingga masing-masing anggota kelompok harus melaksanakan tanggung jawabnya sendiri agar tugas selanjutnya dalam kelompok bisa dilaksanakan. 3) tatap muka: Setiap kelompok harus diberikan kesempatan untuk bertatap muka dan berdiskusi, agar terjadinya interaksi yang akan memberikan keuntungan bagi semua anggota. 4) komunikasi antar anggota: Keberhasilan suatu kelompok juga bergantung pada kesediaan para anggotanya untuk saling mendengarkan dan kemampuan mereka untuk mengutarakan pendapat mereka. 5) evaluasi proses kelompok: Pengajar perlu menjadwalkan waktu khusus bagi kelompok untuk mengevaluasi proses kerja dan hasil kerja mereka agar selanjutnya bisa bekerjasama dengan cara yang lebih efektif. (Annisa Rahmi Yanti Z, dkk, (2014). Salah satu tipe yang bisa diterapkan dalam penelitian ini adalah Teams Games Tournament (TGT).

Teams Games Tournament (TGT) merupakan salah satu tipe dari model pembelajaran kooperatif. Pembelajaran kooperatif tipe TGT adalah salah satu tipe pembelajaran kooperatif yang mudah diterapkan, menyenangkan, melibatkan aktivitas seluruh siswa tanpa harus ada perbedaan status, melibatkan peran siswa sebagai tutor sebaya dan mengandung unsur permainan dan penguatan.

Sedangkan pengertian yang disampaikan oleh Abdus Salam, dkk (2015) dalam Malaysian Online Journal of Educational Technology menyebutkan bahwa:

“Tournaments (TGT) was originally developed by David DeVries and Keith Edwards (1972) at the Johns Hopkins University. It is a type of cooperative learning method. The students compete with members of other teams to contribute points to their team score. 


\title{
J PK (J urnal Pendidikan Khusus), 14 (2), 2018 - 72
}

\author{
Rafika Rahmawati
}

Students compete in at least three-person "tournament tables" against others with a similar past record in mathematics. After then a procedure changes table assignments to keep the competition fair. The winner at each tournament table brings the same number of points to his or her team, regardless of which table it is; this means that low achievers and high achievers have an equal opportunity for success. High performing teams earn team rewards."

Menurut Slavin (2005: 163) TGT adalah model pembelajaran dimana para siswa berlomba sebagai wakil dari tim mereka dengan anggota tim lain yang kinerja akademik sebelumnya setara seperti mereka. Pembelajaran diawali dengan anak bekerja sama menyelesaikan tugas dalam satu kelompok, kemudian salah satu anak mewakili kelompoknya untuk berlomba dengan kelompok lain. Selanjutnya Trianto (2009: 83) menjelaskan TGT adalah model pembelajaran dimana siswa memainkan permainan dengan anggota-anggota tim lain untuk memperoleh tambahan poin untuk skor tim mereka.

Manfaat dengan menggunakan TGT salah satunya adalah "In addition, cooperative learning TGT also creates an active learning environment in solving exercises, and discussions among students and teachers. This study provides evidence that learning probability with TGTs benefits students." Berdasarkan pendapat di atas maka TGT juga menciptakan lingkungan pembelajaran aktif, latihan dan diskusi di antara siswa dan guru. (Arsaythamby Veloo, Sitie Chairhany, 2013).

Selain itu, menurut Vidal Garcia \& Marta Esmeralda (2014) dalam XI Journa'ls Internacionales de Innovacion Universitaria Educar menyebutkan bahwa:

"In a similar vein, Light (2001) identified that student learning teams are extremely effective; students learn considerably more and are better prepared. An alternative to the individual assessment is the group assessment, in which students are allowed to support each other in their learning tasks. Taking all of that into consideration, a classroom method involving all those benefits is the Teams-Games-Tournament (TGT) technique, first developed by DeVries and Edwards (1973) and later improved by DeVries and Slavin (1978), as a useful cooperative learning technique to assess a course. TGT is an alternative to traditional assessment methods such as individual tests. It is based on group cooperation to achieve common goals. Students learn to compete among them in a healthy way through cooperative work.

Adapun maksut dalam pernyataan di atas maka dapat ditarik kesimpulannya adalah sebagai berikut: Dengan nada yang sama, Light (2001) mengidentifikasi bahwa tim belajar siswa sangat efektif; siswa belajar lebih banyak dan lebih siap. Alternatif bagi individu penilaian adalah penilaian kelompok, di mana siswa diperbolehkan saling mendukung dalam tugas belajar mereka. Mengambil semua itu menjadi pertimbangan, metode kelas melibatkan semua manfaat itu adalah Teams-GamesTournament (TGT) teknik, pertama dikembangkan oleh DeVries dan Edwards (1973) dan kemudian ditingkatkan oleh DeVries dan Slavin (1978), sebagai teknik pembelajaran kooperatif yang berguna untuk menilai suatu kursus. TGT adalah sebuah alternatif untuk metode penilaian tradisional seperti tes individu. Itu didasarkan pada kerja sama kelompok untuk mencapai tujuan bersama. Siswa belajar berkompetisi di antara mereka cara yang sehat melalui kerja kooperatif.

Adapun keuntungan dan kelemahan dengan menggunakan TGT adalah sebagai berikut:

Advantages and Disadvantages of Teams Games Tournament (TGT) According Shoimin (2014: 207), TGT model have several advantages and disadvantages. The advantages of TGT such as: The first is TGT method not only make students with high ability, but students are capable of academic lower will push to active, and have an important role in the group. Second is this learning method can develop a sense of cooperation and mutual respect between students in her group members. The third makes the students enthusiastic about the course. Because in this study, the teacher make an agreement about the rewards will be given for the students as the best group. Finally is the students become more active and interested in the class because there is activity in the form of tournament games in this model. There are also several disadvantages of TGT methods such as; The first is takes a long time, because the educators must establish conditions prescribed in the application of TGT.Second is the teachers are required to be good at choosing the subject matter suitable 


\section{J PK (J urnal Pendidikan Khusus), 14 (2), 2018 - 73}

Rafika Rahmawati

for this method. The last is the teacher must prepare before it is applied, for example, to create questions for each table tournaments or competitions, and teachers need to know the size of the learners who are academically highest to lowest.

Berdasarkan paparan di atas maka dapat ditarik kesimpulan sebagai berikut: Keuntungan dan Kerugian Game Tim Turnamen (TGT) menurut Shoimin (2014: 207), model TGT memiliki beberapa kelebihan dan kekurangan. Keuntungan dari TGT seperti: Yang pertama adalah metode TGT tidak hanya membuat siswa dengan kemampuan tinggi, tetapi siswa yang mampu akademis lebih rendah akan mendorong untuk aktif, dan memiliki peran penting dalam grup. Kedua, metode pembelajaran ini dapat mengembangkan rasa kerjasama dan saling menghormati antara siswa dalam anggota kelompoknya. Yang ketiga membuat siswa antusias tentang kursus. Karena dalam penelitian ini, guru membuat kesepakatan tentang imbalan yang akan diberikan untuk siswa sebagai kelompok terbaik. Akhirnya para siswa menjadi lebih aktif dan tertarik di kelas karena ada aktivitas dalam bentuk permainan turnamen dalam model ini. Ada juga beberapa kelemahan metode TGT seperti; Yang pertama adalah memakan waktu yang lama, karena pendidik harus menetapkan kondisi yang ditentukan dalam penerapan TGT. Kedua adalah para guru dituntut untuk pandai memilih mata pelajaran yang cocok untuk metode ini. Yang terakhir adalah guru harus mempersiapkan sebelum diterapkan, misalnya, untuk membuat pertanyaan untuk setiap turnamen meja atau kompetisi, dan guru perlu mengetahui ukuran peserta didik yang secara akademis tertinggi ke terendah.

Salah satunya adalah TGT (teams games tournament). Dimana dalam permaianan ini memiliki beberapa kelebihan diantaranya 1) Para siswa memperoleh teman yang secara signifikan lebih banyak 2) Meningkatkan perasaan/persepsi keberhasilan dari kinerja, 3) Keterlibatan siswa lebih tinggi dalam belajar bersama, dan 4) Menumbuhkan tanggung jawab, kejujuran, kerja sama, persaingan sehat antar sesama. Sedangkan untuk kelemahannya adalah kemampuan guru dalam mengelompokan siswa secara heterogen. (Agus Puji Astutik, 2014)

Model pembelajaran kooperatif tipe TGT memiliki beberapa langkah yang harus diterapkan.Langkah-langkah pembelajaran TGT menurut Slavin (2005: 166-167) adalah:

a. Presentasi kelas, yaitu mengenalkan materi pembelajaran secara klasikal.

b. Tim, yaitu membagi siswa yang terdiri antara 4-5 anak yang memiliki kemampuan, jenis kelamin, dan suku atau ras yang berbeda.

c. Game, siswa bekerja di dalam tim dan memastikan bahwa seluruh anggota tim telah menguasai pelajaran.

d. Turnament, yaitu salah satu siswa mewakili kelompoknnya untuk bertanding dengan anggota kelompok lain dan memberikan kontribusi nilai terhadap kelompok mereka.

e. Rekognisi tim, yaitu penghargaan terhadap tim yang dapat mencapai skor sesuai kriteria.

Permainan dapat disusun dosen dalam bentuk turnamen berupa pertanyaan-pertanyaan yang berkaitan dengan materi pelajaran. Gambaran umum pelaksanaan pembelajaran kooperatif tipe TGT sebagai berikut: a) presentasi kelas, pada awal pembelajaran dosen menyampaikan materi. Pada tahap ini mahasiswa diharapkan dapat berkonsentrasi penuh selama penyajian materi karena hal ini akan membantu mahasiswa untuk dapat menjawab soal pada saat turnamen. b) belajar kelompok, kelompok terdiri atas 4 atau 5 orang yang anggotanya heterogen dilihat dari kemampuan akademik. Fungsi utama dari kelompok ini adalah untuk memastikan bahwa semua anggota kelompok benarbenar belajar untuk mempersiapkan anggota kelompoknya mengerjakan turnamen yang akan diadakan pada akhir pembelajaran nanti. Setelah dosen menyampaikan materi, kelompok berkumpul untuk mempelajari lembar kegiatan yang diberikan dosen.

Aturan dalam kelompok antara lain setiap mahasiswa mempunyai tanggung jawab untuk memastikan bahwa teman satu tim mereka telah mempelajari materinya, tidak ada yang boleh berhenti belajar sampai semua teman satu tim menguasai pelajaran tersebut, mintalah bantuan dari semua teman satu tim untuk membantu temannya sebelum teman mereka itu bertanya kepada guru. teman satu tim boleh berbicara satu sama lain dengan suara pelan, tekankan kepada siswa bahwa mereka belum selesai belajar sampai mereka yakin bahwa teman satu tim mereka akan mendapatkan poin untuk turnamennya nanti. c) Tahap Pelaksanaan Turnamen. (Annisa Rahmi Yanti Z, dkk, (2014)).

Penggunaan model pembelajaran kooperatif tipe TGT memiliki manfaat yaitu anak terlibat aktif dalam kegiatan main sehingga dapat memotivasi untuk meningkatkan kemampuannya, 


\section{J PK (J urnal Pendidikan Khusus), 14 (2), 2018 - 74}

Rafika Rahmawati

sebagaimana dikemukakan oleh Isjoni (2009: 16) bahwa dalam kerjasama, anak terlibat aktif pada proses pembelajaran sehingga berdampak positif terhadap kualitas interaksi dan komunikasi anak serta dapat memotivasi anak untuk meningkatkan kemampuannya.

\section{PROSEDUR KEGIATAN}

Kegiatan penerapan inovasi pembelajaran ini dilaksanakan pada perkuliahan di semester gasal, perkuliahan mata kuliah Pengembangan Komunikasi Alternatif dan Augmentatif untuk Anak Hambatan Majemuk.

1. Perencanaan

Inovasi pembelajaran yang dilakukan untuk mata kuliah pengembangan komunikasi alternatif dan augmentatif adalah Team Games Tournament (TGT). Inovasi ini dilakukan untuk meningkatkan keaktifan dan rasa percaya diri, sehingga kontribusi mahasiswa berkebutuhan khusus dalam perkuliahan tampak nyata. Pelaksanaan inovasi pembelajaran berupa team games tourmanent dilaksanakan pada perkuliahan ke-6 sampai dengan ke-9. Pada tahap ini kelas yang memiliki jumlah 10 orang mahasiswa dibagi menjadi 5 kelompok, dimana masing-masing kelompok berjumlah 2 orang, dan masing-masing kelompok tersebut akan melakukan asesmen terhadap seorang anak yang mengalami hambatan majemuk. Area asesmen yang akan menjadi sasaran pengamatan adalah kondisi komunikasi anak hambatan majemuk dan kemampuan komunikasi yang masih bisa dikembangkan.

2. Pelaksanaan

Subjek dalam kegiatan ini melibatkan seluruh mahasiswa dalam satu kelas, mahasiswa semester 5, yang mengambil kekhususan Pendidikan Anak Hambatan Majemuk, dengan fokus pada seorang mahasiswa yang mengalami hambatan komunikasi.

a. Profil mahasiswa berkebutuhan khusus

JS (inisial) adalah mahasiswa jurusan Pendidikan Luar Biasa semester 5 yang mengambil kekhususan hambatan majemuk. Mahasiswa ini memiliki hambatan komunikasi. Saat berkomunikasi dengan menggunakan bahasa verbal, ada beberapa artikulasi dan bahasa yang sulit ditangkap oleh lawan bicaranya. Suara yang dominan keluar dari mahasiswa ini saat berbicara verbal adalah suara yang parau dan cenderung sengau. Saat semester-semester awal perkuliahan, mahasiswa ini terlihat menggunakan alat bantu dengar pada salah satu telinga nya, yaitu telinga sebelah kiri.

Dalam kesehariannya mahasiswa ini bergaul secara wajar dengan mahasiswa yang lain. Namun memang cenderung mengerjakan apapun sendiri tidak melibatkan orang lain atau mahasiswa lain tetapi tidak menarik diri dari lingkungan teman-teman sekelasnya. Dalam kelas JS ini cenderung diam dan sangat sedikit sekali berinteraksi dengan teman sekelasnya. Ketika diajak berinteraksi JS ini bisa nyambung dan merespon dengan wajar, namun sangat minim ketika JS yang mengawali pembicaraan atau interaksi dengan orang lain. Keaktifan didalam kelas saat mengikuti perkuliahan juga tidak terlalu nampak bahkan cenderung pasif, sebagai contoh ketika dosen menjelaskan JS tidak pernah mengajukan pertanyaan atau berkomentar apapun, namun ketika ada pancingan dari dosen yang menanyakan sesuatu berkait tema perkuliahan yang diberikan, dia dapat menjelaskan. Prestasi nya tidak tertinggal dari teman sekelasnya cenderung biasa dan ada di level menengah.

b. Profil Mata Kuliah

Mata kuliah Pengembangan Komunikasi Alternatif dan Augmentatif adalah pembelajaran yang akan memberi pemahaman tentang konsep komunikasi alternatif dan augmentatif yang akan diterapkan untuk anak dengan hambatan majemuk. Mata kuliah ini merupakan mata kuliah pada kekhususan pendidikan anak hambatan majemuk. Kegiatan dalam mata kuliah ini akan mencakup konsep komunikasi alternatif dan augmentatif; program asesmen tentang kebutuhan anak hambatan majemuk terhadap komunikasi alternatif dan augmentatif; pemilihan model dan alat komunikasi alternatif dan augmentatif; serta penerapan rancangan program pengembangan komunikasi alternatif dan augmentatif terhadap anak dengan hambatan majemuk. Dalam perkuliahan ini digunakan penilaian terhadap pengamatan sikap dan tanggungjawab dalam melaksanakan tugas, penilaian produk berupa laporan kegiatan lapangan yang tertuang dalam sistematika hasil laporan dan ketajaman analisis hasil laporan. 


\section{JPK (J urnal Pendidikan Khusus), 14 (2), 2018 - 75}

Rafika Rahmawati

Pelaksanaan inovasi pembelajaran team games tournamaent, di kelas semua kelompok di beri kesempatan untuk mempresentasikan hasil pengamatan lapangan mereka, termasuk kelompok dari JS. Saat presentasi tersebut JS menjadi presenter untuk kelompoknya, sehingga dia memiliki kesempatan untuk berbicara didepan kelas. Saat selesai presentasi semua kelompok atau masing-masing individu di kelas diberi kesempatan untuk mengajukan pertanyaan dan argumentasi mereka. Dan team yang menjadi presenter hari dapat memberikan klarifikasinya terkait pertanyaan yang diajukan. Yang terjadi pada pelaksanaan inovasi team games tournament ini, JS mampu menjadi presenter untuk kelompoknya dengan baik, mampu mengklarifikasi atas pertanyaan yang masuk ke kelompoknya, namun saat kelompok lain yang melakukan presentasi joko tidak memberi masukan apapun, namun masukan dan pertanyaan diajukan oleh rekan se-tim nya.

\section{SIMPULAN}

Melihat hasil inovasi yang dilakukan pada tahap awal yang sesuai dengan target yang ditetapkan dan juga dalam pelaksanaannya tidak ada kendala yang berarti, maka inovasi ini akan dilanjutnya sesuai dengan rencana yang telah disusun. Selanjutnya, apabila di hasil akhir perkuliahan menunjukkan dampak yang positif terhadap mahasiswa baik mahasiswa umum maupun mahasiswa berkebutuhan khusus, maka inovasi pembelajaran berupa team games tournament akan tetap digunakan pada mata kuliah pengembangan komunikasi alternatif dan augmentatif untuk anak hamabtan majemuk. Sebagai tindak lanjut dari inovasi pembelajaran ini, akan disusun kembali inovasi pembelajaran pada mata kuliah yang lain sesuai dengan karakteristik kebutuhan masing-masing mahasiswa.

Tidak ada kendala yang berarti dalam pelaksanaan team games tounament ini, pada saat kelompok JS tampil ke depan untuk presentasi dia mampu menjadi presenter dengan pemaparan yang baik dan mampu memberikan klarifikasi dengan baik pula. Kelemahan JS masih muncul berupa belum munculnya inisiatif JS untuk bertanya kepada kelompok lain saat kelompok lain menyampaikan presentasinya.

\section{DAFTAR PUSTAKA}

Abdus Salam, dkk. 2015. Effects of Using temas Games Tournaments (TGT) Cooperative Technique for Learning Mathematics in Secondary Schools of Bangladesh. Bangladesh: Malaysian Online Journal of Educational Technology (MOJET) Volume 3, Isuue 3.

Annisa Rahmi Yanti Z, dkk, (2014). Pengaruh Pembelajaran Kooperatif Tipe Teams Games Tournament Terhadap Hasil Belajar Matematika Di Kelas Viii Smpn 2 Bukittinggi Tahun Pelajaran 2013/2014. Vol. 3 No. 1 (2014) : jurnal Pendidikan Matematika, Part 1 Hal. 1-5. Staf Pengajar Jurusan Matematika FMIPA UNP. https://eprints.uny.ac.id/9630/1/JURNAL\%20SKRIPSI.pdf. Rindang Penerapan TGT.

Agus Puji Astutik. 2014. Penggunaan Metode Team Game Tournament untuk Meningkatkan Keterampilan Bercerita pada Anak Autis. Malang: Universitas Negeri Malang dalam Jurnal Ortopedadodia, Volume 1, Nomor 3, Desember 2014: 245-250.

Arsaythamby Veloo, Sitie Chairhany. 2013. Fostering Student's Attitudes and Achievement in Probability Using Teams- Games-Tournaments. Malaysia: Procedia Social and Behavioral 93 (2013) 59-64 Sciences Science Direct.

Isjoni \& Ismail, M. A. (2008). Model-model pembelajaran mutakhir (perpaduan indonesiamalaysia). Yogyakarta: Pustaka Pelajar.

Liliweli, Alo. 1997. Komunikasi Antar Pribadi, Bandung : Citra Aditiya Bakti.

Slavin. E. R.( 2005). Cooperative learning teori, riset dan praktik. Penerjemah: Narulita Yusron. Bandung: Nusamedia. 
JPK (J urnal Pendidikan Khusus), 14 (2), 2018 - 76

Rafika Rahmawati

Shoimin, A. (2014). 68 model pembelajaran inovatif dalam kurikulum 2013.Yogyakarta: Ar- Ruzz Media.

Trianto.(2009). Mendesain pembelajaran inovatif progresif. Jakarta: Kencana Prenada Media Group.

Vidal Garcia \& Marta Esmeralda (2014). Knowledge Competition: An Entertaining and Useful Way to Review Concepts that Would Enable Students to Develop others Underlying Skills. Education and Professional Development Department School of Social Sciences Universidad Europea. XI Journa'ls Internacionales de Innovacion Universitaria Educar 